\title{
Ramón Gómez de la Serna oder die Avantgarde im Café
}

Mit dem späten César Vallejo haben wir bereits biographisch wie thematisch wieder den europäischen Kontinent und zugleich jene Ereignisse berührt, welche die Intellektuellen Europas wie Amerikas in ungeheure Erregung versetzen sollten. Ich meine natürlich den Putsch gegen die Zweite Spanische Republik, der nach dem Bürgerkrieg zur Machtergreifung des „Generalísimo“ Franco führte und ein Vorspiel der faschistischen Kriege wie des Weltkriegs bot.

Auch jene literarische Figur, mit der wir uns im Folgenden in der gebotenen Kürze beschäftigen wollen, konnte jenen historischen Ereignissen nicht fremd bleiben, zählte aber nicht zu den politischen Akteuren, sondern lediglich zu den vielen, welche die Ereignisse erlitten und vom „Franquismo“ ins Exil getrieben wurden. Ramón Gómez de la Serna kehrte, wie sehr er auch in Spanien und insbesondere in Madrid verwurzelt war, seinem Heimatland gleich zu Beginn der Kriegshandlungen den Rücken und suchte sich die argentinische Hauptstadt als künftigen und - wie sich zeigen sollte - endgültigen Mittelpunkt seines literarischen Lebens aus. Auch dies mag neben vielen anderen Indizien belegen, wie sehr in der ersten Hälfte des 20. Jahrhunderts, nachdem Spanien im Jahr 1898 im Spanisch-Kubanisch-US-Amerikanischen Krieg seine letzten Kolonien in Amerika verloren hatte, die ehemalige „Madre Patria“ und die amerikanische Hispanität geokulturell einander wieder nähergekommen waren.

Freilich hatte die Entscheidung Ramóns - wie er sich stets liebevoll nennen ließ und wie er bis heute auch in der Forschungsliteratur genannt wird - vor allem biographische Gründe. Allem ungeachtet war und blieb Ramón Gómez de la Serna schlicht und ergreifend „madrilenissimo“, also ein Madrilene von altem Schrot und Korn. Wir sollten uns daher auch mit den Anfängen der Avantgarde in Madrid und in jenen Zirkeln kurz beschäftigen, die sich einerseits in die europäische Tradition der Kaffeehausliteratur und andererseits in jene der spanischen „Tertulia“ einschreiben. An dieser Stelle seien nur einige wenige Biographeme des spanischen Schriftstellers genannt, die uns ein wenig mit dem zeitgeschichtlichen Kontext Don Ramóns vertraut machen sollen.

Ramón Gómez de la Serna wurde am 3. Juli 1888 in Madrid geboren und verstarb am 12. Januar 1963 in Buenos Aires, also in seinem argentinischen Exil. Sein Vater war Generaldirektor der Katasterämter, Jurist und selbst Schriftsteller, seine Mutter die Nichte der spanischen Dichterin Carolina Coronado: Ramón war also erblich vorbelastet. Gómez de la Serna studierte Jura, wurde Anwalt und schrieb als Journalist zahlreiche Artikel, in denen er als Verteidiger der neuen Avantgarden auftrat. Er zeigte schon früh eine starke literarische Begabung und versuchte 
sich in seinem schriftstellerischen Leben in nahezu allen Gattungen, vom Roman über den Essay bis hin zu Mikrofiktionen, die er als Greguerias bezeichnete und von denen er unendlich viele verfasste.

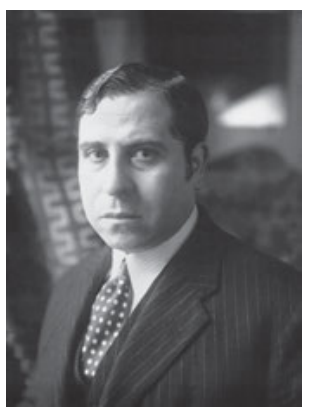

Abb. 66: Ramón Gómez de la Serna (Madrid, 1888 - Buenos Aires, 1963).

Don Ramón gründete einen berühmten madrilenischen Literatenzirkel im Café Pombo, eine Tertulia, wie sie charakteristisch war für die spanische Kultur- und Geistesgeschichte. ${ }^{1}$ Neben seiner Arbeit als Journalist war er als Organisator von Happenings überaus aktiv: Er veranstaltete Abende, die durchaus an die futuristischen „serate“ wie an die dadaistischen Auftritte im Zürcher Voltaire erinnerten. Ramón wurde zum Inbegriff der avantgardistischen Literaten- und Künstlerszene, reiste 1933 nach Buenos Aires und kehrte wegen des ausgebrochenen Spanischen Bürgerkrieges nicht mehr in sein Heimatland zurück.

Gómez de la Serna war eine der vielseitigsten Begabungen der spanischen Avantgarde: Er machte sich als Romancier, Novellist, Essayist, Biograph, Verfasser von Dramen und Gedichten, als Autor von Kunstbüchern und Herausgeber von Anthologien einen Namen und veröffentlichte über hundert Bände. Seine von einem starken Humor geprägten „Greguerías“ machten ihn berühmt: Bis zu seinem Tod gab er sie mehrfach in Sammlungen heraus, die seinen literarischen Ruhm sowohl diesseits wie jenseits des Atlantik begründeten und festigten. Diese Greguerías finden sich aber auch in nahezu allen seiner Werke, sowohl in seinen Biographien - u. a. von Goya (1917), El Greco (1935), Ramón del Valle-Inclán (1944) oder Quevedo (1953) - als auch in seinen autobiographischen Schriften wie Automoribundia von 1948 oder Nuevas páginas de mi vida von $1957^{2}$

1 Vgl. hierzu die Habilitationsschrift von Gelz, Andreas: Tertulia. Literatur und Soziabilität im Spanien des 18. und 19. Jahrhunderts. Frankfurt am Main: Vervuert 2006.

2 Vgl. Scarano, Laura: Automoribundia de Ramón Gómez de la Serna: heterodoxia autobiográfica de un vanguardista insólito. In: Iberoamericana (Madrid - Frankfurt am Main) IX, 36 (diciembre 2009), S. 47-56. 


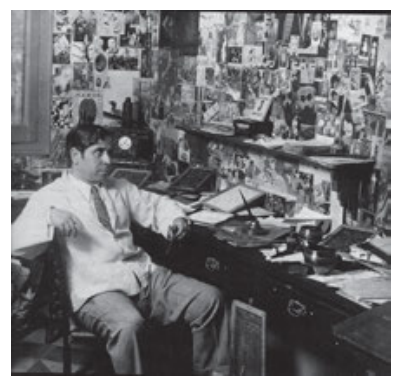

Abb. 67: Ramón Gómez de la Serna in seinem Atelier in der Calle de Villanueva, Madrid, Anfang der 1930er Jahre.

Wir haben es bei Ramón Gómez de la Serna mit einem Vielschreiber und Allroundschriftsteller zu tun, in dessen Werk gleichwohl die kurzen Formen, welche Roland Barthes einmal als „écriture courte“ bezeichnete, einen ganz besonderen Stellenwert einnehmen. Sie bilden so etwas wie das verdichtete Herzstück des gesamten Schaffens dieses spanischen Avantgardisten. Ich möchte daher auch diesen kürzeren Formen ein besonderes Gewicht in Hinblick auf unsere Vorlesung geben und zugleich eine weitere Dimension, jene von Körperlichkeit und Sexualität, aber auch Brechung sexueller Tabus, in unsere Vorlesung einblenden beziehungsweise thematisch weiterführen. Es ist bereits jetzt unschwer zu ersehen, wie breit und vielfältig die literarischen Arbeiten der historischen Avantgarden ebenso in Europa wie in Übersee waren.

Schon früh war Ramón Gómez de la Serna mit der Literatur hautnah in Berührung gekommen; und sein wohlsituierter Vater ermöglichte es ihm ökonomisch, mit Hilfe der von ihm finanziell wohl ausgestatteten Zeitschrift Prometeo, einen Ausgangs- und zugleich Kristallisationspunkt der literarischen und künstlerischen Kreativität für den talentierten Sohn zu schaffen. Doch es blieb nicht bei dieser literarischen Gemeinschaft und Kollektivität, welche ein Zeitschriftenprojekt immer darstellt: Die Aktivitäten Don Ramóns umfassten bald auch eine spezifische Form spanischer Geselligkeit, die - wie bereits kurz angedeutet - auf eine jahrhundertealte Tradition zurückblicken konnte. Sie spielte in den Zirkeln der spanischen Aufklärung eine wesentliche Rolle, sollte aber gerade an der Jahrhundertwende und zur Entstehungszeit der spanischen Avantgarden eine ganz besondere Bedeutung erlangen: die „Tertulia“. Was für Frankreich über Jahrhunderte hinweg die Salons waren, das waren für Spanien die Tertulias mit ihren so spezifischen Formen von Soziabilität. Und wie es in Frankreich auch heute noch literarische Salons gibt, so bestehen auch die Tertulias in Spanien fort.

Wir können unter einer Tertulia zunächst einmal eine freie und offene, aber regelmäßige Versammlung von Menschen unterschiedlicher Herkunft zumeist an einem öffentlichen oder halböffentlichen Ort verstehen, wobei sich jede einzelne Tertulia spezifische Formen der Leitung und des Beisammenseins gibt. Eine Tertulia kann, eher angelehnt an französische Modelle, in den vier Wänden 
eines an bestimmten Tagen geöffneten Privathauses stattfinden, oder aber was wesentlich häufiger ist - in jener öffentlichen Atmosphäre angesiedelt sein, welche die Kaffeehäuser größerer und großer Städte bieten. Berühmt sind noch heute die Tertulias etwa im Café Gijòn, die über ein hohes Sozialprestige verfügen, zumal das Gijón in Madrid auch einen eigenen Literaturpreis vergibt. $\mathrm{Zu}$ meiner Studentenzeit in Madrid machte es großen Spaß, sich mit den literarisch gebildeten und oft über Insider-Kenntnisse verfügenden Kellnern des Café Gijón zu unterhalten. Einer Tertulia anzugehören und sich regelmäßig jede Woche in einem Café zu treffen, um in wechselnden Zusammensetzungen über Literatur zu diskutieren, gehörte für Studierende der „Letras“ an der Complutense zu Madrid einfach dazu.

Sicherlich ist das Kaffeehaus eine geradezu gesamteuropäische Institution, die bisweilen in gesellschaftlichen und politischen Auseinandersetzungen je nach Land eine wichtige Rolle spielte. Doch kommt wohl in keinem Land Europas der öffentlichen Versammlung im Café eine so bedeutsame, für die literarische und gesellschaftliche Kommunikation insgesamt so entscheidende Rolle zu wie der Tertulia in Spanien. Wir sollten dabei nicht vergessen, dass wir es im Verlauf unserer Vorlesung schon einmal mit einem Café zu tun hatten, dem Café Voltaire nämlich, in dem sich im Zürich des Ersten Weltkriegs eine internationale Gruppe zumeist emigrierter Literaten und Künstler traf, um den Dadaismus aus der Taufe zu heben. Unterschätzen wir also nicht die Bedeutung der Kaffeehäuser für Literatur und Kunst.

Derart radikal wie im dadaistischen Café Voltaire ging es in den madrilenischen Cafés nicht zu; doch war auch hier deren Öffentlichkeit Ausgangspunkt für eine Literatur- und Kunstpraxis, die Privates und Öffentliches, Produktion und Rezeption, vor allem aber Kunst und Leben zusammendenken sollte und wollte. Die Kunst sollte wie die Literatur nicht länger autonomisiert für sich sein; vielmehr sollten Leben und Literatur, Leben und Kunst eine Einheit und Ganzheit bilden, welche nicht auseinandergetrieben werden konnte. Das Bild des einsamen Schriftstellers am Schreibtisch in seiner Bibliothek, das auch in den Portraits des Fin de siècle wie des „Fin de siglo“ so stark vertreten war, galt nicht länger. Literatur und Kunst sollten an die Öffentlichkeit und gelebt werden: Das Leben sollte Kunst, die Kunst sollte Leben werden!

Nicht umsonst war für Ramón Gómez de la Serna das Café jener Ort, wo man - ihm wie auch vielen Avantgardisten dieser Epoche zufolge - am besten schreiben konnte: für jeden sichtbar, für jeden ansprechbar, für jeden berührbar. Erinnern Sie sich noch an den ,Writer in Restaurant“ bei Enrique Vila-Matas gleich zu Beginn unserer Vorlesung? Das war eine avantgardistische Reminiszenz wie so vieles, was sich in den Werken dieses spanischen Schriftstellers oft sehr humorvoll und mit einem kräftigen Schuss Ironie versehen tummelt. 
Nun werden Sie sicherlich einwenden, dass sich das alles nach französischen Existentialisten-Zirkeln anhört, also ein wenig nach Boris Vian oder Jean-Paul Sartre, der in den Deux magots viele seiner Texte unter den Augen des Publikums schrieb. Auch das Café Flore verdankt jenen Zeiten seinen bei Touristen heute ungebrochenen Ruhm. Aber so hatte ich es gerade nicht gemeint! Vielmehr versammelte man sich in der begrenzten Öffentlichkeit des Cafés, um die verschiedensten aktuellen Dinge, vor allem aber die neuesten Entwicklungen in der Literatur, Kunstentwicklung und Ästhetik zu diskutieren. Oft lud man in die Tertulia zusätzlich Literaten und Künstler ein, integrierte gerade in Madrid durchreisende Literatinnen und Literaten, um deren Vorstellungen $\mathrm{zu}$ hören und $\mathrm{zu}$ erfahren, wie man in Montevideo, Berlin, London oder Paris dachte. Eine Tertulia ist niemals ein abgeschlossener Kreis, sondern eine stets für Gäste und Reisende offene Versammlung, in der man gerne neue Autor^innen und neue Ansichten persönlich kennenlernte - ein Ort, an dem man auch Literatur und Kunst zu betreiben pflegte: eine Kunst, die vor allem auf das mündliche Wort und auf die flüchtige Skizze abzielte. Denn es waren das Vorübergehende und Flüchtige, das Hingeworfene und Spontane, die einen ganz besonderen Stellenwert in einer Tertulia erlangten: Gerade das schnell entstandene, das schnell geäußerte Wort, die unwiederholbare Kombinatorik von Inszenierungen, Diskussionen, Konflikten und Debatten - die Schnelligkeit in der Hervorbringung von Kunst, die Schlagfertigkeit in der Reaktion auf Literatur waren gefragt. In alledem galt Ramón Gómez de la Serna als der unbestrittene Meister.

Diese für Spanien so charakteristische Soziabilität und Geselligkeit liebte außerdem den spezifisch spanischen Witz, von der „broma“ bis zum „chiste“. So verwundert es nicht, dass Ramón Gómez de la Sernas schriftstellerisches Werk sich auch in seiner schriftlichen Form durch den grundlegenden und sehr eigenen Humor des Verfassers auszeichnete. Auch in anderen Teilen der spanischsprachigen Welt bildete diese Dimension von Humor und Witz eine wichtige Grundlage für Entwicklungen gerade in der Avantgarde. Denken wir nur an die Insel Kuba mit ihrem auf Grund der kolonialen Erfahrung so hintergründigen Humor, an ihren sehr spezifischen „choteo“, ${ }^{3}$ in welchem hinter den vordergründig geäußerten Worten - wie in einer Kolonialgesellschaft häufig - andere gemeinte, aber nicht geäußerte Worte zum Vorschein kommen!

3 Vgl. Campa, Román de la: Caribbean Post-Modernity, Cuban choteo, and „The Repeating Island“. In: Apuntes Postmodernos / Postmodern Notes (Miami) VI-VII, 1-2 (Spring - Fall 1996), S. 2-15; Rodríguez Gutiérrez, Milena: El choteo de la cubanidad. In: Encuentro de la cultura cubana (Madrid) 47 (2008), S. 12-17; sowie Bennett, Andrew: Una nación burlona: Virgilio Piñera y el „,hoteo“ cubano. In: Cuadernos Americanos (México) XXIX, 153 (Julio - Septiembre 2015), S. 49-66. 
Don Ramón Gómez de la Serna gründete seine Tertulia, seinen bald schon berühmten Zirkel von Literat*innen und Künstler`innen, im Madrider Café Pombo, unweit der Puerta del sol, in einem sehr madrilenischen und damals auch schon angestaubten Café, in dem sich auf eigenartige Weise das Alte und das Moderne miteinander verbanden. In diesem Ambiente entwickelte sich das, was Don Ramón selbst einmal als die „pombianische Ästhetik“ bezeichnete. Mechthild Albert ${ }^{4}$ hat dieser Ästhetik einmal einen eigenen Artikel gewidmet und mit guten Gründen von der Tertulia als dem Laboratorium der spanischen Avantgarde gesprochen. In der Tat lassen sich viele Belege dafür finden, in dieser spezifischen Art von Soziabilität die Keimzelle der besonderen Avantgardeentwicklung in Spanien zu erblicken. Doch sehen wir uns zunächst einmal die Texte von Gómez de la Serna selbst näher an! Denn das Café wird bei ihm zu einem geradezu mythisch verklärten Ort, an dem einfach alles möglich ist. Im folgenden Zitat wendet sich Ramón in einer seiner zahlreichen Reden aus Anlass irgendeines Banketts an seine Tischgenossen:

\footnotetext{
Liebe Kameraden im Pombo,

Es scheint so langsam, dass wir eine literarische Gruppe mit einer bestimmten Ästhetik repräsentieren, der Pombianischen Ästhetik, und es ist nicht wahr, damit kann man uns nicht belangen. Wie sehr wünschten sie, dass wir eine sichtbare Ästhetik hätten mit einem Kopf, um den man uns kürzer machen könnte! [...]

Unsere Ästhetik kann bestenfalls, kann ihren Ausgang finden bestenfalls von einer Konzeption dieses Lokals, und das ist nicht wenig! [...]

Das Barocke ist etwas alarmierend, obgleich dies eine sympathischere Klassifizierung ist als die anderen. Das Barocke nimmt recht gut das Zerzauste, das Zerstörte, das Konfuse, das Blasphemische, das Intensive auf.

Unsere Ästhetik ist eine „Pombianische“. Wir sind die „Pombianer“. Und damit Schluss. ${ }^{5}$
}

Wir können feststellen: Ramón Gómez de la Serna war sich in diesem Zitat bewusst, dass der von ihm im Jahre 1909 geschaffene Zirkel, der bis zu seinem Verlassen von Madrid fortbestehen sollte, eine tiefe Wirkung auf die zeitgenös-

4 Vgl. Albert, Mechthild: Para una estética pombiana: la tertulia, laboratorio de la vanguardia española. In: Martín, Hernández, Evelyne (Hg.): Ramón Gómez de la Serna. Clermont-Ferrand: CLRMC 1999, S. 103-120; sowie des Weiteren dies.: Imaginiertes Amerika, erinnertes Spanien, erlebtes Argentinien: Ramón Gómez de la Serna in Buenos Aires. In: Lang, Sabine / Blaser, Jutta / Lustig, Wolf (Hg.): „Miradas entrecruzadas“ - Diskurse interkultureller Erfahrung und deren literarische Inszenierung. Beiträge eines hispanoamerikanischen Forschungskolloquiums zu Ehren von Dieter Janik. Frankfurt am Main: Vervuert 2002, S. 299-313.

5 Gómez de la Serna, Ramón: Discurso (1919). In (ders.): Pombo. La sagrada cripta del Pombo. Madrid - Triest: Ed. De Andrés Trapiello 1986, S. 232. 


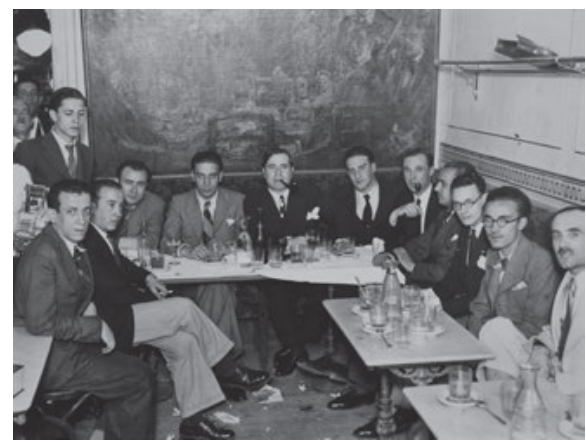

Abb. 68: Tertulia des Café Pombo im Jahr 1932.

sische Literaturszene ausgeübt hatte und dass die Mitglieder dieses Zirkels, dieser Tertulia, sehr wohl als eigenständige literarische Gruppe wahrgenommen wurden. Er unterstellte all jenen, die von dieser Gruppe sprachen und ihr eine griffige Ästhetik unterstellten, die Absicht, diesen Zirkel zu zerschlagen. Gleichzeitig aber verband er nicht ohne Ironie die avantgardistische Ästhetik mit der jener Lokalität, die man für die öffentlichen Auftritte und Inszenierungen nutzte. Insofern lässt sich die These, die Tertulia sei das Laboratorium der spanischen Avantgarde gewesen, mit Blick auf Ramón Gómez de la Serna sicherlich halten. Für eine pombianische Ästhetik aber brauchte es mehr!

Die Tertulia - soviel können wir an dieser Stelle festhalten - ist im spanischen Literaturbetrieb auch noch im 20. und 21. Jahrhundert ein wichtiges, wenn auch heute vielleicht etwas verblassendes Faktum, eigentlich eine soziale und literarische Institution von größter Tragweite, welche sich übrigens selbst auch als Institution begreift. Vergessen wir nicht, dass beispielsweise das Café Gijón auch heute noch einen eigenen renommierten Literaturpreis vergibt! Was bedeutet aber eine solche Institution? Ist sie etwa mit Bürgers „Institution Kunst“ in Beziehung zu setzen? Was ist die Ästhetik eines Café namens Pombo? Und was ist unter einer „Pombianischen Ästhetik“ zu verstehen?

Ramón Gómez de la Serna hat sich selbst mit den verschiedensten Orten in Madrid, aber auch mehrfach mit dem Café Pombo selbst sehr intensiv literarisch beschäftigt und letzterem zwei umfangreichere Texte - neben vielen kürzeren gewidmet. Das obige Zitat zeigt uns, wie sehr diese Ästhetik an einen Ort und an eine Zeit gebunden ist, also - vergleichbar mit den italienischen Futuristen keine übergreifenden Normen und Werte schaffen will, sondern am Ephemeren, Spontanen und Raschen, übrigens auch am Simultanen, interessiert ist. Die spanische Avantgarde geht sehr eigene Wege und entwickelt eigene literarische und soziale Strategien.

Vor allem geht sie ins Café zur Tertulia, um sich wechselseitig zu befruchten und um einen Teil ihrer eigenen Kunst zu erleben und zu leben. Die Gespräche 
und kleinen Aufführungen bei derartigen Tertulias bilden bei den Avantgardisten ein häufiges literarisches Sujet; und noch bei den spanischen Autoren nach den historischen Avantgarden finden sich zahllose Beispiele für derartige in die Literatur eingegangene Gesprächsrunden. Übrigens wurde in den zwanziger Jahren einmal eine solche Sitzung im Café Pombo für den spanischen Rundfunk teilweise mitgeschnitten, und es soll eine recht unterhaltsame, kurzweilige und witzige Veranstaltung gewesen sein.

Es ist gerade diese Dimension der Mündlichkeit und der unmittelbaren schlagfertigen Reaktion in dem, was Gómez de la Serna mehrfach die Stunde der Wahrheit nannte, die für diese Ästhetik der Schnelligkeit und des Ephemeren von grundlegender Bedeutung sind. Zugleich kamen anderen Elementen wie dem Zufall, der Kontingenz und dem Spielerischen, aber auch dem Anzapfen des „Unterbewussten“, wie man das noch vorfreudianisch nannte, eine wichtige Funktion zu. Denn es sind ja gerade die Schnelligkeit und die Signifikanz des Zufalls, die dem Schreiben wie der Kunst insgesamt jene artistischen Kontingenzen bescheren, in welchen ihnen das Unbewusste gleichsam - wie bei den französischen Surrealisten - zufällt.

Des Weiteren kommt dabei besonders den Zeichnungen eine wichtige Rolle zu und allerlei ludischen Einbettungen von Skizzen und Grafiken, wobei ich auf die verschiedenen Formen des Spiels nicht eingehen kann, sondern nur erwähnen möchte, dass auch hier Gómez de la Serna, der gerne vieles kategorisierte, um sich dann darüber hinwegzusetzen, unter anderem die Form der „Kleksografía“ erfand. All diese künstlerischen Ausdrucksformen sind gleichsam typische Formen des Lebens im Café, bis hin zu jenen sogenannten Mosaiken, die die Dichter in Form einzelner Worte oder Reime auf die Kaffeetische schrieben, um damit gegen die von den Kellnern stets von neuem aufgemalten Zahlen und Rechnungen aufzubegehren.

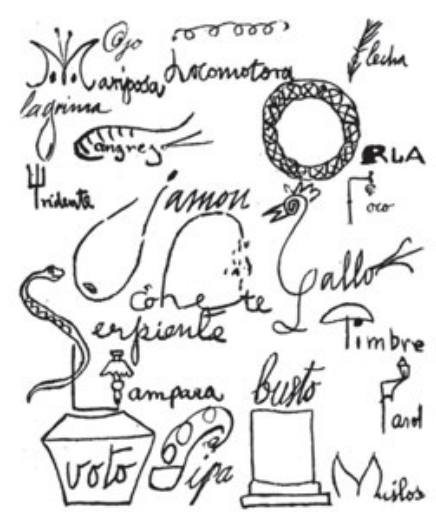

Abb. 69: Pombianische Skizzen. 

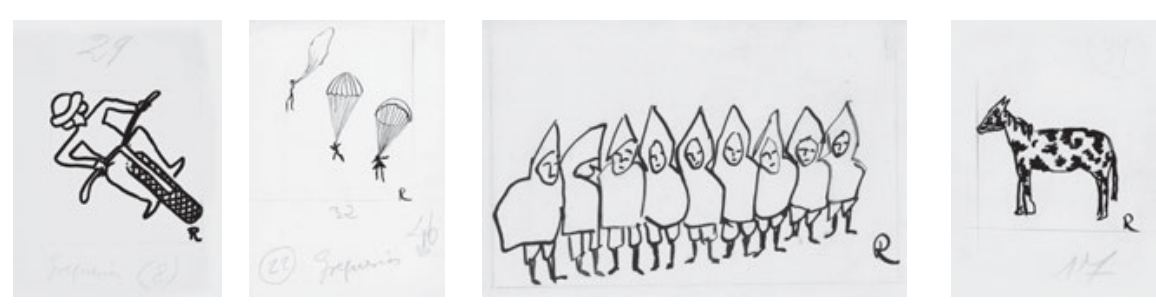

Abb. 70a, b, c und d: Ramón Gómez de la Serna: Greguerías.

Bei allen Parallelen, die bislang zum italienischen Futurismus, zum internationalen Dadaismus oder auch zum französischen Surrealismus - mit dem wir uns gleich im weiteren Fortgang beschäftigen werden - in der neueren Forschungsliteratur hergestellt wurden, ist doch unverkennbar, dass den spanischen Avantgarden eine weitaus geringere Stoßrichtung mit Blick auf den Traditionsbruch eigen war. Und mehr noch: ein wesentlich geringerer Wille, mit den bisherigen literarischen, künstlerischen oder soziopolitischen Traditionen radikal zu brechen. Die Institution der Tertulia selbst, aber auch die Orte der Öffentlichkeit, an denen sich diese neue Kunst manifestierte, waren letztlich traditionalistisch geprägte Lokalitäten, denen nur eine neue Wendung, ein etwas fremdes und überraschendes Aussehen gegeben wurde, ohne doch deren Traditionslinien erschüttern zu wollen. So überrascht es auch nicht, dass wir im Café Pombo keineswegs bloß ausgemachte Avantgardisten, sondern auch Vertreter der Generación del 98 wie Ramiro de Maeztu oder des Modernismus wie Ramón del Valle-Inclán antreffen können, die ebenfalls - wie viele spanische Literaten - die Öffentlichkeit der Cafés als Diskussionsforen liebten. Wir stoßen in Spanien folglich auf Kontinuitäten, die wir bereits in Lateinamerika vorgefunden hatten und die belegen, dass es sehr eigene avantgardistische Ausdrucksformen in der spanischsprachigen Welt gibt, welche wir keinesfalls auf die mitteleuropäischen Avantgardevorstellungen reduzieren dürfen.

So ist auch eine der Hauptformen der avantgardistischen Literatur von Ramón Gómez de la Serna, die „Greguería“, eine literarische Form des Aphorismus, die uns durchaus aus der Barockzeit bereits vertraut ist. Nicht umsonst hatte Don Ramón eine gewisse Sympathie im obigen Zitat für die Zurechnung seiner Ästhetik zum Barock bekundet. Wir konnten konstatieren, dass für den spanischen Avantgardisten diese Zurechnung keineswegs eine Beleidigung darstellte, sondern ihm als durchaus „sympathisch“ erschien. So war die Bezugnahme auf das Barock gleichsam eine Bezugnahme auf die literarhistorische Tradition eines gewissen Bruches, auf das Blasphemische und vor allem das Seherisch-Mystische, wie es sich vor allem in den großen spanischen Mystikern ausgedrückt hatte. In erster Linie evozierte sie aber jene Intensität, in welcher wie wir sahen auch Marinetti 
einen zentralen Bestandteil seiner und - par extension - aller futuristischen Kunst erblickte. Doch wo die Futuristen auf den Bruch setzten, da betonten die spanischen Avantgardisten bei aller Innovation die Kontinuitäten innerhalb einer pombianischen Ästhetik.

Intensität, Überraschung, Verdichtung, Geschwindigkeit, Simultaneität: All dies sind Begriffe, die nach kurzen und kürzesten literarischen Ausdrucksformen verlangten und Kurzschreibweisen notwendig machten. Ramón versuchte, diesen Notwendigkeiten durch die spezielle Entwicklung einer literarischen Kleinform zu entsprechen, die er schon mit zwanzig Jahren zu kultivieren begann und die er sein ganzes Leben über hegte und pflegte: die „Greguería“. Was aber ist darunter zu verstehen?

Ramón Gómez de la Serna hat selbst einmal diese literarische Kürzestform auf die griffige Formel „Greguería gleich Metapher plus Humor“ gebracht. Das hilft uns - wie oft bei Ramóns Theorien - so schrecklich nicht weiter, da nicht alle Greguerías dieser Vorstellung oder Definition wirklich entsprechen. Doch zeigt uns die Formel sehr wohl die Blickrichtung und einige Ingredienzien dieser nanophilologischen Kleinform an. Denn der Metapher, also einer Bewegung des Übertragens, kommt eine zentrale Bedeutung genauso zu wie dem Humor und damit auch dem Spielerischen, dem Ludischen, das in der Tat für Gómez de la Serna ebenfalls durchgängig von herausragender Bedeutung war.

Um wirklich zu verstehen, was Greguerías eigentlich sind und wie sie gelesen werden können, möchte ich Ihnen einige erste Beispiele vor Augen führen. Literarische Beispiele einer Kürzestschreibweise, die aus den Jahren 1911 und 1912 stammen:

Welch hübsche kleine Eidechse erwartet mein Schweigen in meinen Bauchnabel, um sich zu sonnen!

Ein Vogelauge, ein Vogelauge, ein Vogelauge über der Stadt macht alles eindruckslos und zeigt die Naivität der Augen des Heiligen Geistes, welche voll sind mit einer dem Vogelauge identischen Theorie.

Warum lassen die Uhren wie im Einverständnis ihr Tick-Tack mit anderen Uhren erschallen, die doch die Stunde früher oder später angeben?

Denken wir doch mit den Lungen, die eine alles andere übertreffende Nachgiebigkeit und Intuition besitzen.

Schaut man die Straßenlaternen an, so erklärt sich die ganze groteske Künstlichkeit der Stadt. 
Die Frauen mit langen nackten Beinen sind voller Melancholie und schuldiger an Menschlichkeit. ${ }^{6}$

Konzentrieren wir uns fürs Erste auf diese wenigen hier zusammengestellten frühen Greguerías von Don Ramón: Sie zeigen die Struktur von Augenblicksaufnahmen, die zumeist syntaktisch, in der Zahl der Sätze sehr knapp gehalten sind und die Satzgrenze in der Regel nicht überschreiten. Äußerste syntaktische Verknappung der sprachlichen Form ist mithin ein erstes wesentliches Element dieser nanophilologischen Strukturen. Ein zweites Element ist unzweifelhaft die Rückführung auf die Position eines Ich, im Übrigen eines männlichen Ich, so dass ein gewisser autobiographischer Grundzug nicht zu übersehen ist, welcher freilich immer mit der Aura genereller Erkenntnis umgeben ist. Ein drittes Element ist die distanzierte Kontemplation, die beispielsweise schon in der ersten Greguería beim eigenen Körper mit der Eidechse beginnt, die sich in der Nabelschau des Ichs und in ihrer Schönheit sonnt.

Ein damit unmittelbar verbundenes viertes Textelement ist die auffällige Körperlichkeit, wobei ebenso die männliche Körperlichkeit des Ich erscheinen kann wie auch die Körperhaftigkeit eines (zumeist intensiv betrachteten) Gegenübers. Dieses Gegenüber ist in aller Regel weiblich modelliert und figuriert: Es tritt oft in seiner Nacktheit auf, wofür wir auch später noch Beispiele sehen werden. Doch es gibt auch von jeder Geschlechtlichkeit abgezogene oder abstrahierende Überlegungen wie etwa zu jenem Denken der Lungen, die dem Erzähler zufolge viel fähiger, verformbarer und intuitiver sind als alles, was wir sonst zum Denken nutzen könnten. In diesen frühen Greguerías von Don Ramón beobachten wir eine sehr körperliche und augenblickshafte Fundierung der kurzen Momentaufnahmen, die in der Regel - und dies ist ein fünftes Element - präsentisch gehalten sind.

Ein weiteres, sechstes Element ist ohne Zweifel die Stadt und ihr urbanes Ambiente. Sie taucht bereits in ihrer Allgegenwart und mit ihren Besonderheiten in diesen frühen Greguerías auf. Die Straßenlaternen erscheinen als die grotesken Repräsentantinnen des Städtischen, des Urbanen, wenn auch offengelassen wird, ob es sich noch um die schönen madrilenischen Gaslaternen handelt oder bereits um eine elektrische Umrüstung, welche emblematisch für die Moderne steht. Es könnte sich durchaus bereits um elektrische Straßenlaternen handeln, da die Elektrifizierung im Kontext der Modernisierung der Städte auch in Spanien rasch voranschritt und Don Ramón bereits wenige Jahre später den

6 Gómez de la Serna, Ramón: Greguerías 1911/1912. In (ders.): Greguerías. Hg. von Rodolfo Cardona. Madrid: Cátedra 1979, S. $219 \mathrm{f}$. 
gelben Birnen der Stadtbeleuchtung in der Provinz eine andere schöne Greguería widmete.

dabei ist die Beleuchtung, also auch gerade die nächtliche Szenerie, für die Stadt nicht weniger wichtig als die Erfassung ihrer Grundstrukturen aus der Luft, aus der Vogelperspektive, die in diesen Kürzesttexten viermal angeführt und mit einer quasi-göttlichen Perspektive verglichen wird. Doch ist diese göttliche Perspektive - wie wir ja bei den Futuristen sahen - zu jenem Zeitpunkt bereits vom Menschen erobert worden in Form jener Flugzeuge, welche sie nun ihrerseits okkupieren. Doch anders als in den futuristischen Manifesten eines Marinetti wird bei Ramón Gómez de la Serna nichts narrativiert: Seine frühen Greguerías bleiben - und dies ist ein siebtes Textelement - Mikrotexte (wie etwa auch Aphorismen), ohne sich in Mikroerzählungen oder gar „Microrrelatos“ zu verwandeln. Diese narrative Entwicklung stand ihm freilich offen, und er sollte sie für sich entdecken und nutzen.

Häufig tritt zur Dimension des Raumes die Dimension der Zeit hinzu, die beständig fortschreitet und alles in ihren Ablauf, in ihre ständig sich beschleunigende Bewegung mitreißt. Dass gerade diese immer wieder auftauchende Erfahrung der Zeit in der hier zitierten Greguería in die Frageform gekleidet ist, mag wiederum diese ständige Beschleunigung noch vergrößern. Denn alle Uhren gehen anders - und doch rückt die Zeit unerbittlich voran: Diese lineare Zeit bringt als ein achtes Textelement in diese Kürzesttexte einen Hauch von „memento mori“, was der aphoristischen Kurzschreibweise der Greguerías gut zu Gesicht steht.

Die Gleichzeitigkeit des Ungleichzeitigen wird überdies in ein sehr treffendes, unmittelbares Bild und mehr noch in eine Metapher gepackt, wobei den in diesen Greguerías verwendeten Metaphern ein nicht allzu großes Maß an Humor - der gleichwohl nicht völlig fehlt - beigegeben ist. Ich würde sogar von einer gewissen Melancholie sprechen, die nicht nur die Frauen mit den langen nackten Beinen, sondern diese Texte Ramóns insgesamt erfasst. Nicht umsonst ist es gerade diese Melancholie, für welche die nackten Frauenbeine als Beschuldigte oder Angeklagte der Menschlichkeit stehen, folglich diese Menschlichkeit in ihrer Melancholie gleichsam verkörpern. Ich komme auf die Visionen des weiblichen Körpers, welche nicht allein die Greguerías, sondern das gesamte Schreiben von Ramón durchziehen und prägen, noch ausführlich zurück. Festzuhalten aber gilt es, dass es diese Körperlichkeit ist, die das aphoristische, scheinbar unmittelbare Schreiben auszeichnet, ebenso wie sie es ist, welche auch in den Zeichnungen zum Ausdruck kommt, die im Café Pombo zu Madrid angefertigt wurden.

Wir könnten mit den verschiedenen Interpretationen und Deutungen der bereits zitierten Greguerías noch fortfahren; doch möchte ich Ihnen lieber weitere Beispiele vorführen, um zusätzliche Aspekte in dieser literarischen Kleinstform bisweilen können die Greguerías die Seitengrenze aber auch überschreiten - auf- 
zudecken. Dabei sollten wir uns vor Augen halten, dass diese Mikrotexte vor allem auch darauf beruhen, dass sie einzeln wirken. Zugleich erschließen sich ganz andere Bedeutungsebenen, wenn sie im Verbund miteinander und damit kotextuell gelesen werden, insofern ihre Leserschaft die Möglichkeit hat, zwischen ihnen immer wieder hin- und herzuspringen, somit gleichsam eine Art gleichzeitiger, simultaner Betrachtung selbst $\mathrm{zu}$ inszenieren und das Gesamtbild immer wieder neu zu verändern.

Dabei ist klar, dass die Lesegeschwindigkeit dieser Greguerías zweifellos niedrig liegt, dass die kurzen Texte folglich sehr aufmerksam und wiederholt gelesen werden müssen. Dies gilt selbstverständlich auch für jene Texte, welche aus den Jahren 1920 bis 1927 stammen und die veränderte Charakteristika aufweisen:

Der klügste Apparat der Welt ist der Wasserfall auf der Toilette, mit dessen Kette in der Hand wir alle der wunderwirkende Moses sind.

Ein Arbeiter mit Brille ist beklagenswert. Mit Hilfe seiner Brille entdeckt er genauer die Ungerechtigkeiten seines Schicksals, sieht dieses besser, sieht es wie ein Herr, wie ein Mann der Wissenschaft, wie ein Intellektueller. Diese Arbeiter mit Blaumann und Brille machen die Sklaverei ihrer Genossen noch trauriger, und sie scheinen eine andere Behandlung zu verdienen, insofern sie sich auf anderes verstehen und sich nur aus Fatalität auf die harte Arbeit einlassen mussten. Ihre Brillen rufen nach Barmherzigkeit und machen keine Genossen, ihr Blick ist gefürchtet.

Es gibt eine frühe Morgenwolke, die wie das Biskuit oder der Blätterteig ist, den der Himmel frühstückt. Sie verschwindet in einem einzigen Augenblick, ohne zu wissen wie, vom hungrigen Blau verschluckt.

Es gibt Wolken, die wie Wollflocken sind, die dem Himmelskissen entkamen, an irgendeiner Ecke aufgetrennt.

Der Lärm der Straßenbahn ritzt das Glasfenster der Nacht.

Dem Sommer in Kastilien fehlen bloß noch einige frei herumstreichende Löwen. ${ }^{7}$

Diese „Microtextos“ von Ramón Gómez de la Serna zeigen zum einen deutlicher die Funktionsweise des ramonianischen Humors, der etwa in der ersten Greguería sich ein Emblem der Moderne, nämlich das Water Closet herauspickt, jenes WC, das schon in der avantgardistischen Form des Readymade und als Fontäne

7 Gómez de la Serna, Ramón: Greguerías 1920/1927, S. 227 ff. 
bezeichnet bei Marcel Duchamp Karriere machte. Es wird von Don Ramón mit der christlich-jüdisch-abendländischen Tradition verbunden, insofern in kühner Metaphorik der rauschende Sturzbach eines Wasserspülungsklosetts mit jenem Wasserfall in Verbindung gebracht wird, den einst Moses durch sein Anschlagen eines Stockes an den Felsen zur Verwunderung und Freude aller mit göttlicher Hilfe hervorzauberte. Das Alttägliche wird damit zum Göttlichen, das Göttliche zugleich auch auf die Dimensionen des Alltäglichen zurückgestuft. Wir waren bereits auf dieses „chassé-croisé“ der Sakralisierung des Profanen und der Profanisierung des Sakralen gestoßen.

Die Berührungsfläche zwischen beiden Isotopien ist freilich begrenzt und punktuell, denn andere Bedeutungsebenen schneiden sich nicht hier, sondern verlaufen quasi parallel zu dieser Berührung. Damit hängt der beabsichtigte humoristische Effekt zusammen, insofern man rasch merkt, dass dies eigentlich gar nicht zusammen passen will: Was hat die Toilette mit Moses gemein? Durchaus im Sinne von Sigmund Freuds Der Witz und seine Beziehung zum Unbewussten ist es eine spielerische Inkongruenz, welche das Lachen oder doch zumindest das Lächeln erzeugt, einmal abgesehen davon, dass die Notwendigkeit der Israeliten, zum Lebensmittel des Wassers zu kommen, in krassem Gegensatz zur Notdurft des modernen Menschen steht, sein Wasser irgendwo abschlagen zu müssen. Der hieraus entstehende Kontrast bildet die Grundlage für die Wirkungsweise dieses Mikrotextes, der freilich noch auf die Neuheit der damaligen Erfindung spekuliert oder vielleicht sogar angewiesen ist. Wir ziehen heute zumeist an keiner Kette mehr. Aber immer, wenn ich im Ausland an eine solche Kette gerate, muss ich an Don Ramón denken ...

Der zweite Text innerhalb der obigen Auswahl ist länger und braucht etwas Anlauf. Im Übrigen wird die Satzgrenze ganz selbstverständlich überschritten, erste narrative Ansätze bilden sich heraus. Auch in diesem Mikrotext spielt eine Inkongruenz die Hauptrolle, nämlich die zwischen der Funktion eines Arbeiters und dem Tragen einer Brille, das als Habitus anderen Berufsgruppen und insbesondere den Intellektuellen - und sehen Sie, so rasch schon stoßen wir auf diesen Begriff - zugerechnet wird. Zugleich werden in krassen Ausdrucksformen die ökonomische Ausplünderung der Arbeiterschaft in der Metaphorik der Sklaverei und die ihr zugeschriebene Dummheit in der Metaphorik des NichtGenau-Sehen-Könnens ausgedrückt. Die soziale Problematik einer historisch entstandenen Arbeiterschaft wird in dieser Greguería überdeutlich, auch wenn nicht weniger erkennbar ist, dass sie von außen gesehen und auf der Grundlage einer Gesellschaft beurteilt wird, welche eigentlich auf die Menschen außerhalb dieser Sklavenkaste beschränkt zu sein scheint. Die Erzählerfigur trägt jedenfalls keinen Blaumann. Die Brille ist bei einem Arbeitersklaven aber gleichsam das verstellte Objekt, steht zeichenhaft für jenen Gegenstand ein, welcher nicht an 
dem eigentlich für ihn bestimmten Ort ist, sondern in den Augen eines nicht der Arbeiterklasse Angehörenden deplatziert wirken muss.

Auch die dritte Greguería baut auf einer Inkongruenz auf, und zwar erneut zwischen der Ebene des Alltags (dem Bereich des täglichen Frühstücks) und dem Bereich des Himmlischen, des Kosmischen, ja des Göttlichen. In diesem Mikrotext verschluckt der Himmel die Biskuits der Wolken, eine Metapher, die in der Tat mit einem Humor versetzt ist, der sich aus der Inkongruenz der Ebenen ergibt. Auch hier lassen sich Ansätze des Narrativen erkennen, so dass der Mikrotext Anzeichen einer Mikroerzählung besitzt, die freilich im letzten Satz zurückgenommen wird. Die Anthropomorphisierung des Himmels führt unzweifelhaft in diese Metaphorik eine surrealistische Note ein, die die Bildhaftigkeit des sprachlichen Ausdrucks geradezu überreizt. Man könnte sich leicht ein Bild, am besten ein Gemälde Salvador Dalís vorstellen, ein Gemälde, in dem die Farbe Blau etwas geradezu Bedrohliches besitzen würde.

Die nachfolgende Greguería könnte den Vers eines Gedichts darstellen, das uns allein in diesem Fragment überliefert wurde. Die Sprünge der Metaphorik sind fast konventionell: Sie gehen zunächst von einem Geräusch einer fahrenden Straßenbahn, also erneut eines urbanen und modernen Elements aus und treffen auf das, was eben keinen oder kaum einen akustischen Schall durchlässt, dafür aber Licht, das freilich nicht erscheint, da es Nacht ist. In gewisser Weise bremsen sich die einzelnen Sinneswahrnehmungen gegenseitig aus, so dass dieser Mikrotext an seinem Ende wirklich an ein Ende kommt. Doch wird er beständig durch die Spiegelungen und Echowirkungen zurückgeworfen, welche sich aus der Tatsache ergeben, dass die im Text aufgebaute Spannung als solche nicht aufgelöst wird. Natürlich verstehen wir, dass die Geräusche einer des Nachts fahrenden Straßenbahn störend sein können; aber dies wäre als städtisches Alltagsphänomen ja eher banal. Die Greguería enthält sehr wohl diese Banalität, funktioniert aber auf der Ebene der Sinneswahrnehmungen recht komplex: Denn das Aufeinandertreffen von Geräusch und Optik, von Hörsinn und Gesichtssinn kulminiert in dem kleinen Wörtchen „raya“, ein Ritzen, das eben Geräusch produziert und das Fenster tendenziell unbrauchbar macht. Dieser Mikrotext ist auf Grund seiner verbalen Narrativstruktur sehr wohl als eine Mikroerzählung, als ein „Microrrelato“ zu bezeichnen. Don Ramón nähert sich damit einer literarischen Gattung an, welche ab der zweiten Hälfte des 20. Jahrhunderts besonders in der spanischsprachigen Welt Amerikas einen fulminanten Aufstieg erleben sollte. ${ }^{8}$

8 Vgl. hierzu u. a. die Tagungsbände von Ette, Ottmar / Ingenschay, Dieter / Schmidt-Welle, Friedhelm / Valls, Fernando (Hg.): MicroBerlín. De minificciones y microrrelatos. Madrid - Frankfurt am Main: Iberoamericana - Vervuert 2015; und Ette, Ottmar / Sánchez, Yvette (Hg.): Vivir lo breve. 
Ramón Gómez de la Serna war für die Herausbildung dieses Genre ein wichtiger Vorläufer.

Sie sehen: Man kann diese Mikrotexte durchaus kommentieren, analysieren, interpretieren und mit literarhistorischen Entwicklungen in Verbindung bringen. Rodolfo Cardona hat dies einmal bestritten und gemeint, man könne die Greguerías ebenso wenig erklären wie Witze, die zerfallen, nähme man sich ihrer auf analytische Weise an. Ich glaube als überzeugter Literaturwissenschaftler und Nanophilologe jedoch daran, dass man den Genuss eines Textes noch dadurch erhöhen kann, dass man bestimmte Dimensionen von Texten oder Mikrotexten analysiert und schärfer herausarbeitet. Denn Literaturwissenschaft ist im Sinne von Hugo Friedrich eine genießende Wissenschaft und Analyse bekommt dem Genuss - entgegen aller Unkenrufe - sehr wohl!

In jedem Falle scheint es mir wichtig zu verstehen, wie sehr die Polysemie diese kurzen Texte auszeichnet, die wie der Witz von der Schnelligkeit, von der Geschwindigkeit leben. Die Liebe der historischen Avantgarden zu diesen kurzen Texten könnte im Übrigen mit jener der Neo-Avantgarden $\mathrm{zu}$ anderen kurzen Texten in Verbindung gebracht werden, die in der Form des Haiku als Erbe japanischer Provenienz durch die abendländischen Literaturen des 20. sowie des 21. Jahrhunderts geistern. Es ist bei Haikus das blitzartige Erkennen, das Aufleuchten einer eigentlich unsagbaren Wahrheit, das in den gegen einander laufenden Versen dieser strengen kurzen Gedichtform zum Vorschein oder besser noch zum Aufscheinen gebracht wird. Freilich ist die Form des Haiku wesentlich stärker reglementiert und streng geordnet. Ramóns Greguerías hingegen sind außer ihrer Verknappung - die auch nicht überall zum Äußersten getrieben wird - eine literarische Kleinform mit hohem Gestaltungsspielraum.

Wenn wir von der Liebe der Neo-Avantgarden zu den Kurz- und Kürzesttexten sprechen, so sollten wir darüber auch nicht vergessen, die Tendenz mancher Theoretiker dieser Neo-Avantgarden zur verkürzten, zur verdichteten Form anzusprechen. Für diese Gruppe ist sicherlich Roland Barthes ein ausgezeichnetes Beispiel, insofern sich Barthes sehr häufig einer Kurzschreibweise, der - wie er selbst es nannte - „écriture courte“ widmete, die er in seinem wunderbaren Buch Le Plaisir du texte, seiner Lust am Text, ${ }^{9}$ ebenso auf den theoretischen wie auf den ästhetischen Punkt gebracht hat.

Nanofilología y microformatos en las letras y culturas hispánicas contemporáneas. Madrid - Frankfurt am Main: Iberoamericana 2020.

9 Vgl. hierzu Barthes, Roland: Die Lust am Text. Aus dem Französischen von Ottmar Ette. Kommentar von Ottmar Ette. Berlin: Suhrkamp Verlag 2010. 
Die Greguerías basieren oftmals auf dem Alltäglichen und Banalen, das freilich in andere Zusammenhänge und Ebenen eingerückt wird, durch welche semantische oder kategoriale Inkongruenzen entstehen. So ist die letzte von mir als Beispiel aufgenommene Greguería eigentlich die Umsetzung eines doppelten, Spanien spätestens seit dem 18. Jahrhundert verfolgenden Spruches, demzufolge das Land der Iberer nicht mehr zu Europa, sondern vielmehr zu Afrika gehöre. Außerdem wird die Meseta Kastiliens, zum Teil nicht einmal zu Unrecht, als Wüste bezeichnet; da wäre es nicht schwierig, sich in einer solchen afrikanischen Wüstenlandschaft unter der gleißenden kastilischen Sonne frei herumstreichende Löwen vorzustellen. Dabei dekonstruiert sich der ursprünglich von Franzosen abfällig auf Spanier gemünzte Satz selbst, denn in der Tat fehlen die Löwen, einmal ganz abgesehen von der Tatsache, dass der ganze Satz nur für den Sommer Kastiliens, nicht aber für die anderen Jahreszeiten etwas Geltung beanspruchen darf. Nicht umsonst heißt es ja von Kastilien: „Nueve meses de invierno, tres meses de infierno.“ Alle anderen Ingredienzien freilich wären da, scheint die Greguería zu suggerieren; und doch kommt zu den Löwen noch ein weiteres Element hinzu: Sie befinden sich in Freiheit. Dieses Element der Freiheit aber ist ambivalent und ließe sich auf verschiedene Kontexte beziehen: ebenso auf Spanien selbst, das in seinem Wappen sowohl die Burg (Kastilien) als auch den Löwen (von León) trägt wie auf die Spanier, die sich zum damaligen Zeitpunkt, in den zwanziger Jahren, in sehr ungewissen politischen Verhältnissen befanden.

Sie sehen: Raum zum Nachdenken gibt es bei diesen literarischen Kürzestformen genügend! Dies hat nicht zuletzt damit zu tun, dass die Greguerías vergleichbar mit Gedichten mehr Platz auf der Seite als durchschnittliche Prosatexte beanspruchen, was bedeutet, dass sie umgekehrt proportional hierzu auch eine deutlich langsamere Lesegeschwindigkeit verlangen. Die Mikrotexte von Ramón Gómez de la Serna müssen wie Gedichte mehrfach gelesen werden, sonst entfesseln sie das vieldeutige Spiel mit verschiedenen Versatzstücken aus banaler Alltagswelt, scheinbar unmittelbarer Spontaneität und einer oft beeindruckenden Polysemie nicht. Ihre Schnelligkeit auf der Textebene, die vergleichbar mit der des Witzes ist, steht in einem krassen Gegensatz zur langsamen Lesegeschwindigkeit dieser verdichteten Texte.

Ich möchte mich an dieser Stelle von diesen Mikro- und Simultantexten abund einem Bereich zuwenden, der in der ersten Serie der Greguerías bereits kurz zur Sprache kam: dem Bereich des Körperlichen, der menschlichen Körperlichkeit. Ich meine damit genauer den menschlichen Körper in seiner Nacktheit, wobei der Körper im literarischen Schreiben dieses männlichen Autors in aller Regel ein weiblicher ist. Wir hatten dieses literarische Thema eher ausgespart, waren kurz bei César Vallejo darauf eingegangen und bislang nur in den Zitaten 
von Valentine de Saint-Point darauf aufmerksam geworden, dass die historischen Avantgarden selbstverständlich auch eine genderspezifische Seite besitzen.

In der Tat wäre kritisch zu reflektieren, warum die historischen Avantgarden bislang fast durchgängig als männlich gelten und erscheinen. Die allermeisten avantgardistischen Autoren sind Männer; die Frauen rückten fast immer ins zweite Glied oder nahmen die Rolle der Musen ein. Erst spät scheinen sie sich langsam aus dem Schatten der Männer herauszulösen. Sie tun dies entweder als Frauen, die nun nicht mehr in ihrer Abhängigkeit von Männern, sondern in ihrem eigenen künstlerischen Beitrag erscheinen (wie etwa Frieda Kahlo, die ihren früheren Herrn und Meister Diego Rivera in der Rezeption heute deutlich überragt) oder als Frauen, die sich explizit gegen die Vorherrschaft der Männer wenden (wie etwa Valentine de Saint-Point). Zuvor waren den Frauen nur ganz spezifische Rollen möglich gewesen: in Form von Gegenständen männlichen Schreibens oder männlicher Kunst, folglich verwandelt in Kunstobjekte avantgardistisch orientierter Künstler (und oftmals Lebenspartner), oder - wie etwa bei Marinetti in deutlich negativer, bisweilen misogyner Einfärbung. Oder aber sie galten als Autorinnen und Künstlerinnen, die sich gerade den avantgardistischen Tendenzen und Entwicklungen ihrer Zeit entziehen und andere, eigene Wege jenseits der Avantgarden einschlagen. Dies war etwa bei der ersten lateinamerikanischen Literaturnobelpreisträgerin Gabriela Mistral der Fall, wobei wir uns mit ihr sowie mit Dichterinnen wie Alfonsina Storni oder Juana de Ibarbourou in Lateinamerika noch einmal ausführlich und gesondert auseinandersetzen werden. Festzuhalten bleibt, dass die Spielräume für Frauen in den historischen Avantgarden nicht nur in Lateinamerika, sondern auch in Europa sehr begrenzt waren.

Die Geschlechterdifferenz und Geschlechtlichkeit insgesamt spielen also durchaus eine Rolle in der strukturellen Fundierung der historischen Avantgarden auf beiden Seiten des Atlantiks. Frauen erscheinen allzu oft als Musen und Inspirationsquellen und damit als subalterne Figuren, da sie aus einer machistischen Optik der Natur und ihren Zyklen näher geblieben sind. Zugleich eröffnet diese Dimension des Geschlechtlichen im Verbund mit dem Körperlichen eine weite erogene Zone von Enttabuisierungen, mithin eine Zone, in welcher der avantgardistische Wille, mit überkommenen Normen, Konventionen und Traditionen zu brechen, wahrlich ausagiert werden kann. Wir hatten dies bereits in César Vallejos Gedicht Pienso en tu sexo gesehen.

Dieser Aspekt des Traditionsbruchs als Tabubruchs erscheint nun in unterschiedlicher Stärke und Heftigkeit in verschiedenen Bewegungen und Ismen der historischen Avantgarden. Die spanischen Avantgarden bieten im Vergleich zur späteren Entwicklung im französischen Surrealismus Formen sexueller Enttabuisierung, die dem spanischen Gesellschafts- und Kultursystem stärker angepasst erscheinen. Dort inszeniert man keine so radikalen Brüche wie etwa in Frank- 
reich, wo ein Georges Bataille mit seiner Histoire de l'œil, auf die wir im Rahmen unserer Vorlesung später zurückkommen werden, eine so radikale Entrümpelung von Ausdrucksformen der Körperlichkeit und Sexualität vornahm, dass er aus guten Gründen seinen Text nur unter einem Pseudonym gegen Ende der zwanziger Jahre veröffentlichen konnte.

Ein gutes Jahrzehnt zuvor aber hatte Ramón Gómez de la Serna erstmals einen Band veröffentlicht, der sich schon im Titel explizit einer erogenen Zone des weiblichen Körpers enttabuisierend annäherte und annahm. Mit seiner aus dem Jahr 1917 stammenden Sammlung Senos, in denen wir die „écriture courte“, wenn auch nicht so verdichtet wie in der Form der Greguería, mit Ausdrucksformen der Körperlichkeit, genauer noch: des Frauenkörpers, sich überschneiden sehen. Dieses Buch ist heutzutage, lange Jahrzehnte nach dem Ende des Franquismus und der Liberalisierung beziehungsweise Enttabuisierung bestimmter moralisch zuvor unter Verschluss gehaltener Teile der spanischen Gesellschaft zu einer Art Kultbuch geworden ist und hat in der Folge eine Art „continuation“ gefunden hat: den Band Coños von Juan Manuel de Prada nämlich. ${ }^{10}$ Dies mag uns hier nur am Rande interessieren und dabei vor allem unter dem Gesichtspunkt, dass die Avantgarde auch noch im aktuellen Kulturleben präsent ist und wichtige Impulse für derzeitige literarische und künstlerische Projekte liefert. Aufschlussreicher für uns ist es, mit einer gewissen philologischen Detailfreude zu untersuchen, inwieweit sich in Don Ramóns Senos avantgardistische Elemente ausfindig machen lassen und welche spezifische Form von Geschlechtlichkeit und Körperlichkeit denn in diesem Buch über die Brüste thematisiert und vorgeführt wird.

Beschäftigen wir uns zunächst mit dem Paratext jenseits des provokativen Titels Senos, der etwas krude auf den Inhalt des Buches aufmerksam macht! Die Titelgebung war gewiss aber auch eine Strategie ebenso der antibürgerlichen Provokation wie der avantgardistischen Aufmerksamkeitserregung. Das Vorwort von Gómez de la Serna, der damals zweiundzwanzig Jahre alt und damit noch ein junger Mann war, zur ersten Ausgabe seiner Senos zielte hingegen darauf ab, die Provokation wo irgend möglich abzumildern und selbst nicht in den Verdacht $\mathrm{zu}$ kommen, ein pornographisches Buch geschrieben $\mathrm{zu}$ haben. So lesen wir im Vorwort die eher beschwichtigenden, aber zugleich ironischen Worte Don Ramóns:

10 Vgl. hierzu Ette, Ottmar: Mit Haut und Haar? Körperliches und Leibhaftiges bei Ramón Gómez de la Serna, Luisa Futoransky und Juan Manuel de Prada. In: Romanistische Zeitschrift für Literaturgeschichte / Cahiers d'Histoire des Littératures Romanes (Heidelberg) XXV, 3-4 (2001), S. 429-465. 


\begin{abstract}
Dieses Buch ist kein pornographisches Buch. In ihm gibt es keine Dreistigkeiten, sondern eine Heiterkeit, eine empfindsame Heiterkeit sowie eine ruhige und lächelnde Wertschätzung bezüglich des Spektakels der zahlreichen Brüste, die man in den Gärten des Lebens erblickt. In ihm finden sich die reinsten Verdorbenheiten, distinguierte Verdorbenheiten, in welchen die Verdorbenheit selbst geheilt ist, insofern sie lediglich als Weg zur Klärung diente. An seinem Ende wird sogar die Sünde einer übergroßen Delektation gebüßt, so dass der Geist, dramatisch und problematisch, gereinigt wird.

Die Brüste sind das Plastischste im Geheimnis des Mannes, und dies ist es, was ich hier verbreite und mit aller Erbitterung zum Ausdruck bringe. Vielleicht haben sich die Männer immer außerhalb des Moments bewegt, in dem sich alles in den Brüsten synthetisierte, und dabei auf diese Brüste gewartet; und selbst wenn sie sie vergessen hätten, so haben sie sich doch wie Schlafwandler in ihren Brüsteferien betragen. In den beiden hemisphärischen Sphären, welches die Brüste sind, ist doch die eitle irdische Sphäre noch immer enthalten. Verflucht sei die Mutter derer, die scheinheilig das Nackte verabscheuen, die Mutter, die sich vor dem Vater dieser Männer auszog und deren Nacktheit Anreiz dafür war, dass sie geboren. ${ }^{11}$
\end{abstract}

In dieser Passage des Vorworts beobachten wir eine zunächst eindeutige, sodann aber auch ironische Verteidigungsstellung gegenüber dem erwartbaren Vorwurf der Pornographie. Ramón Gómez de la Serna benutzt dabei dieselbe Verteidigung, welche die französischen Schriftsteller bereits im 19. Jahrhundert im sogenannten Immoralismus-Prozess gegen die französische Literatur anwandten: ${ }^{12}$ eine Mischung aus Behauptung der eigenen Sittenkonformität und einer ironisch unterlegten Aufforderung, gerade die heiklen Stellen als heilende zu lesen.

Eine derartige Doppelstrategie erstaunt nicht in einem Land, in dem wie in kaum einem zweiten in Europa die katholische Kirche in ihrer ambivalenten Haltung gegenüber allem Geschlechtlichen und insbesondere dem weiblichen Körper die Augen und Ohren weiterhin zu verdecken und zu verstopfen versucht im Lichte einer Moral, von der wir seit langen Jahrzehnten wissen, dass sie eine Doppelmoral ist. Ich brauche an dieser Stelle nicht auf die allenthalben dort üblichen Missbrauchsfälle verweisen, welche lange Zeit ungesühnt blieben und stets vertuscht wurden. Ein von der katholischen Presse vorgebrachter Vorwurf der Pornographie jedenfalls lag zweifellos in der Luft - und Don Ramón tat gut daran, ihn sogleich paratextuell, also in seinem Vorwort, aufzugreifen.

Doch der spanische Avantgardist wechselt sogleich die Tonlage: Die Heiterkeit, mit der bereits im Paratext die weiblichen Brüste angekündigt, beschrieben, untersucht, befragt werden, hat gleichsam etwas Ungeschlechtliches, Engelhaf-

11 Gómez de la Serna, Ramón.: Senos [1917]. Segovia: El Adelantado 1923, S. 8.

12 Vgl. hierzu Heitmann, Klaus: Der Immoralismus-Prozeß gegen die französische Literatur im 19. Jahrhundert. Bad Homburg - Berlin - Zürich: Gehlen 1970. 
tes. Dies zumal die hemisphärische Metaphorik nicht allein ein wissenschaftliches Beschreibungselement einführt, sondern dieses auch auf eine halbe Welt, die spanischsprachige Welt in der Südhemisphäre, bezieht. Die primären weiblichen Geschlechtsmerkmale werden so zu einem nicht allein körperlich-biologischen, sondern auch zu einem kulturellen Element, das der Verfasser des Bandes gleich zu Beginn des Buches ausspielt.

So ist auch die Metaphorik vom Garten eine, die nicht allein den Garten Eden aufruft mit der dort vor dem Sündenfall ,natürlichen' Nacktheit von Mann und Frau, sondern auch jenen Garten der Lüste, wie ihn einst Hieronymus Bosch entwarf und in die abendländische Tradition projizierte. Ramón setzt davon freilich eine geradezu abstrakte, losgelöste Position der Brüste ab, die man mit Jacques Lacan als Teile eines „corps morcelé“, eines zerstückelten Körpers, auffassen könnte, wie diese beispielsweise auch in der zeitgenössischen Malerei der Avantgarden projiziert wurden. Die Brüste werden von der Frau gleichsam losgelöst und damit ,abgezogen', folglich abstrakt gemacht - wohlgemerkt: im männlichen Blick auf die weiblichen Brüste!

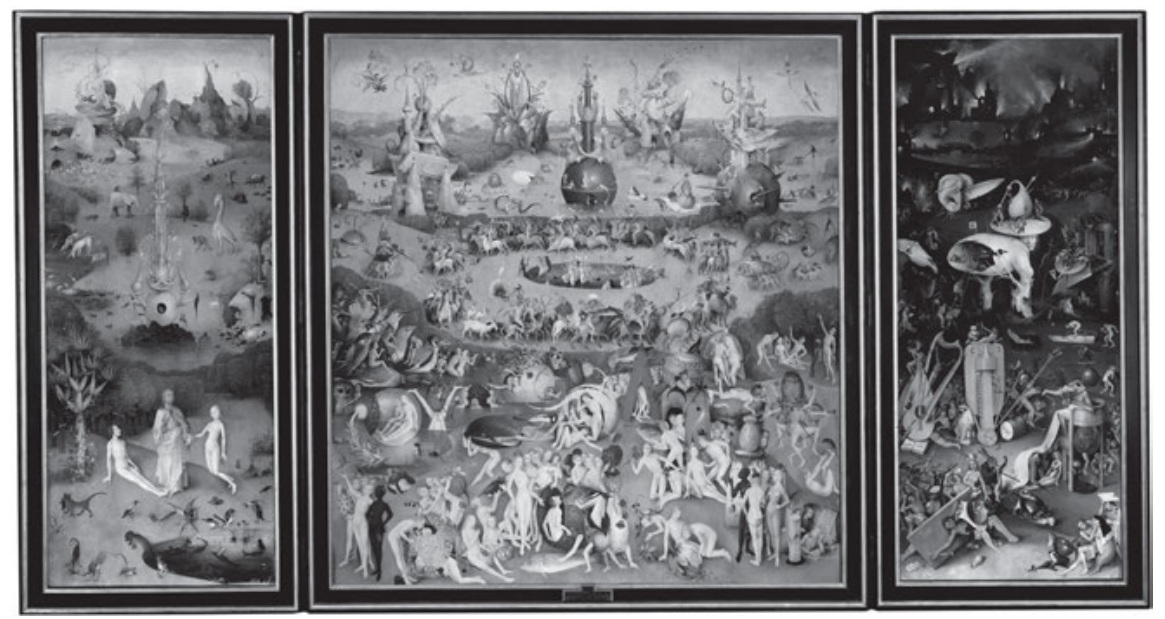

Abb. 71: Hieronymus Bosch: Der Garten der Lüste, Öl auf Eichenholz, zwischen 1490 und 1500.

So ist es eher ein Garten männlicher Freuden und männlicher Erbauung als ein Garten Eden oder ein Garten des Teufels, der Verführung und Verderbtheit, der „depravación“, welche der spanische Schriftsteller weit von sich weist. Ganz konsequent argumentiert das Vorwort dann auch in Hinblick auf seine eigene therapeutische Wirkung, die sich gerade der Depravation entgegenstelle, um auf diese Weise besser und wirksamer dem Sittenverfall und der Verderbnis entgegen- 
wirken zu können. Dies war noch von jeher die Argumentationslinie erotischer Literatur - und mit einer solchen haben wir es hier zu tun. Sie stand immer in der Not, ihr eigenes Vorhandensein durch allerlei moralisierende Kunstgriffe rechtfertigen zu müssen, um als die bessere Austreibung des Ungeistes, als die wirksamere Austreibung des Teufels mit dem Beelzebub, zu gelten. Diese Rechtfertigung musste letztlich immer am Erhalt der guten Sitten und Bräuche ausgerichtet sein.

Doch gibt es auch ein zweites Element, das freilich darin aufscheint, dass es nicht nur eine quasi-wissenschaftliche Selbstbezogenheit der weiblichen Brüste gibt, sondern dass sie auch und gerade ihre eigentliche Funktion in Bezug auf den Mann - ja vielleicht erst durch den Mann - erhalten. Denn die Plastizität ist eindeutig erst mit der Bezogenheit auf die Virilität durch den männlichen Betrachter gegeben und eröffnet ein weites Feld nicht nur für den Fern-Sinn des Auges, sondern auch für die Nah-Sinne des Menschen (und Mannes). Gewiss wird dies insoweit relativiert, als in beiden Hemisphären auch das Irdische enthalten ist, womit hier unzweideutig die Geschlechtlichkeit und deren Pragmatik gemeint sind.

An eben dieser Stelle wird das Vorwort angriffslustig, greift jene Scheinheiligen an, die doch ihrerseits eine Mutter besaßen, welche sich vor ihrem Vater nackt zeigte - und zwar nicht mehr in jener unschuldigen Nacktheit, in der Adam und Eva im Garten Eden zusammengelebt hatten. Denn längst befinden wir uns nach dieser Unschuld im Paradies, ${ }^{13}$ nach der Geburt des erotischen Blicks auf den jeweils anderen Körper: Und sie sahen, dass sie nackt waren. So seien die Scheinheiligen selbst, die jegliche Nacktheit verurteilen, Kinder dieses Blickes und Kinder jener Zeugung, die ohne den erotischen Blick auf das andere Geschlecht niemals entstanden wäre.

Schön und gut, so dürfen wir hier wohl sagen! Aber was nun? Aufschlussreicher als die Argumentationsstrategie Don Ramóns ist nicht nur die Tatsache, dass es ein Bezogen-Sein der Brüste auf den männlichen Betrachter zu geben scheint, ja dass diese weiblichen Brüste erst im männlichen Blick entstehen würden; wir erkennen vielmehr vor allem das Faktum, dass die Nacktheit in unmittelbarem Verhältnis hierzu ein Privileg der Frauen zu sein scheint. Wird doch die Szene vom Erzähler so modelliert, als habe sich der Vater selbst nicht ausgezogen. Aber ist dies die Perspektive des Erzählers oder nicht vielmehr jener Scheinheiligen, welche die Fortpflanzung der menschlichen Spezies allein der heuchlerischen Verbohrtheit dieser Söhne einer fleischlichen Mutter anvertraut? Die Argumenta-

13 Vgl. hierzu Ette, Ottmar: Konvivenz. Literatur und Leben nach dem Paradies. Berlin: Kulturverlag Kadmos 2012. 
tion von Ramón Gómez de la Serna ist hier, so scheint mir, durchtriebener, als es auf den ersten Blick scheinen mag.

Der Prolog macht letztlich klar, dass die Enttabuisierung, die Preisgabe des weiblichen Körpers mit der sexuellen Tabuisierung des männlichen Körpers einhergeht. Er erscheint stets so, als stünde er mit dem Rücken zur Kamera, als wäre er nur eine Art Hilfsingredienz, um die Schönheit der Frau ins rechte Licht zu rücken: eine Positionierung, die bis heute allen heterosexuellen pornographischen Darstellungen eignet. Der männliche Blick auf den weiblichen Körper ist aus diesem Blickwinkel folglich ein sehr stark tabuisierender, welcher den männlichen Körper als Körper der Lust in Wahrheit eskamotiert.

Eben hierin scheint mir die Problematik dieses Buches zu liegen: Nicht etwa in seiner pornographischen Dimension (die dieses Buch in der Tat nicht hat) besteht sie, sondern in seiner unausweichlichen Zweidimensionalität von Geschlechtlichkeit, in seiner überdeutlichen Zuweisung von Geschlechterrollen, und seien diese noch so gut auf die verschiedenen weiblichen Repräsentantinnen übertragen und verteilt. So wird der Mann letztlich zu einem Sammler, der die unterschiedlichsten Brüste in seinem Buch sortiert, stets aber Brüste, die eigentlich nicht mehr ihren Frauen gehören, sondern Brüste, die nur an den Körpern der Frauen gleichsam aufgehängt sind. Sie erfüllen ihren eigentlichen Zweck im Da-Sein, im Zur-Verfügung-Stehen für den Mann. Auf die Problematik des zerstückelten Körpers im Sinne Lacans, die damit zusammenhängt, komme ich gleich zurück.

Ramón Gómez de la Serna war in der Tat ein großer Sammler: gewiss ein Sammler der eigenen Greguerías, aber nicht zuletzt auch einer von Brüsten. So überrascht es nicht, dass es in diesem Buch mit seinen unzähligen kurzen Texten, die jeweils über eine eigene Überschrift verfügen, auch einen kurzen Text mit dem Titel $E l$ coleccionista gibt. Selbstverständlich entspricht letzterem auch ein „Brüste-Verkäufer“, der uns jedoch nicht weiter interessieren soll; denn unser Herz schlägt für den Sammler, weil sich an dieser Figur eine Vielzahl von Aspekten verdeutlichen lässt.

Dabei nähert sich in der nachfolgend geschilderten Szene eine junge schöne Frau dem Sammler und bietet ihm ihre beiden Brüste zur Begutachtung dar. Diese Szene will ich Ihnen vor Augen führen:

Die ihre Brüste anbot, knüpfte ihr Kleid auf wie die Amme, welche dem Doktor die Güte ihrer Milch beweisen will.

Der Brüstesammler war vertraut mit derlei Demonstrationen und betastete wie ein Juwelier die ihm angebotenen Brüste, er lächelte verzaubert.

Welch schöne Brüste für meine Sammlung! Sie bringen mir hier großartige und unvergessliche Brüste ... Sie wissen ja ... Ich werde sie sehen müssen, sobald ich Lust darauf habe, sobald ich mich an sie erinnere ... Ich werde sie nicht in einem Album ablegen können, aber 
werde Ihnen Bescheid geben, wenn ich diese beiden schönen Exemplare meiner Sammlung benötige ...

Täuschen Sie mich auch nicht?, fragte sie kokett.

Nein ... Sie zählen zu den besten in meiner Sammlung ... Ich werde ihnen die Nummer 10 in einem Zertifikat geben, das Sie dann überall vorzeigen können ... Passen Sie auf sie auf, passen Sie gut auf sie auf ... Die besten aus meiner Sammlung gingen verloren und waren über Nacht beschädigt.

Ich werde auf sie aufpassen, damit ich sie Ihnen von neuem anbieten kann ... [...]

Der Sammler vermerkte in einem Buch: „Soledad R ... in der Calle de las Palmas Nummer 84. Opulente und zugleich empfindliche Brüste ... [...] So rein und schön, wie sie sind, empfindet man nicht das Bedürfnis, sie zu berühren. “14

Anhand dieser Passage aus dem „Brüste-Sammler“ werden eine ganze Reihe literarischer und textueller Elemente deutlich. Zum einen zeigt sich anhand dieses Auszuges, dass die Brüste zwar von der Frau getragen und auch gepflegt werden, letztlich auch zu ihrem Stolz und Selbstwertgefühl beitragen, ihre wahre Erfüllung aber nur in Bezug auf den männlichen Betrachter finden. Kein Zweifel: Das ist eine geschlechterspezifische Asymmetrie, welche die Frau und ihre verschiedenen Körperteile zu einem Objekt des Mannes macht! Die Exteriorität der Brüste in Bezug auf ihre Trägerin findet dabei ihre Entsprechung in der Exteriorität bezüglich ihres männlichen Betrachters, der sie zu untersuchen, zu bewerten und zu klassifizieren berechtigt ist.

Dies ist, ohne jede Frage, ein absolut machistischer Standpunkt. Denn der Brüste-Sammler allein befindet über ihren Zustand, ihre Schönheit, ihre Reinheit und stellt ihrer Trägerin ein entsprechendes Zertifikat aus. Die letztere aber macht die Brüste abstrakt, zieht sie von der direkten Körperlichkeit ab und verwandelt sie in optische Objekte, folglich in ein Phänomen der Netzhaut und damit des Fernsinnes des Auges. Sie entzieht sie damit anderen Sinneswahrnehmungen durch Nah-Sinne wie etwa dem taktilen oder haptischen, was direkt vom Sammler in seinem Buch vermerkt wird. Die Ansichten oder Veduten der Brüste gehen auf Seiten des Brüste-Sammlers also unmittelbar in einen Akt des Schreibens über.

Derselbe visuelle Abstraktionsgrad ist im Übrigen auch in einer anderen ,Geschichte' der Senos vorhanden, wo eine Frau auf die Frage, was sie denn in ihren Brüsten bei einer Berührung fühle, unumwunden zugibt, dass sie eigentlich nichts dabei empfinde. Die Brüste sind ihr offensichtlich außerhalbbefindlich, sind als reine Objekte, deren Trägerin sie ist, nicht an die Sinneswahrnehmungen des eigenen Körpers angeschlossen. Eben dies aber ist die Voraussetzung für die Objektivierung der Brüste, für die Verwandlung dieser primären weiblichen

14 Gómez de la serna, Ramón: Senos, S. 29 f. 
Geschlechtsmerkmale in Artefakte oder objektivierbare Sammelgegenstände, welche unabhängig von jenen Frauen, die sie jeweils tragen, gesammelt werden können.

Sie mögen all dies für reine machistische Spielerei oder schlimmer noch für eine männliche Pathologie, für ein behandlungsfähiges Männerleiden, im besten Falle noch für eine pure literarische Erfindung eines durchgeknallten spanischen Autors halten. Dies gestehe ich Ihnen gerne zu! Doch - und dies sei nur nebenbei erwähnt - ist dies alles gar nicht so realitätsfremd, wie es auf den ersten Blick erscheinen mag. Denn ein derartiges Sammeln fand sich in der Tat Anfang dieses Jahrhunderts - um nur ein Beispiel herauszugreifen - bei einem angesehenen Gymnasiallehrer in Basel; und seine Sammlung, die seiner eigenen Familie lange Zeit und bis über seinen Tod hinaus verborgen blieb, landete schließlich vor einigen Jahren sogar in einer Basler Ausstellung. ${ }^{15}$ Er sammelte freilich keine Brüste, sondern Haare, und zwar der Scham seiner Schülerinnen. Die argentinische Schriftstellerin Luisa Futoransky nahm diese Geschichte in ihr Buch Pelos ${ }^{16}$ auf, das in gewisser Weise vergleichbar auf bestimmte Objektivierungsformen von Körperteilen oder Körperbestandteilen reagiert und diese Anekdote in eine literarische Form bringt: „Honni soit qui mal y pense!“

Wir sehen also, dass das, was wir hier im Kontext der historischen Avantgarden diskutieren, längst Gegenstand einer ernstzunehmenden Habilitationsschrift in der Schweiz - übrigens ein gutes Pflaster für Sammler aller Art - geworden ist. Darin stoßen wir auf die Geschichte von jenem honorigen Gymnasiallehrer, der all seine Schülerinnen zu einem bestimmten Zeitpunkt jeweils einzeln zu sich auf eine Tasse Kakao nach Hause einlud, um sie in einem günstigen Augenblick zu bitten, ihm doch als Erinnerung ein Stückchen von ihren Schamhaaren zu schenken. Fast alle benutzten die Schere, die ihnen der freundliche Mann hinhielt; und so gibt es noch heute eine ungeheuer große Sammlung, in welcher der Sammler genau die Namen, das Alter und den Zeitpunkt vermerkte, an dem er diese Zeichen der Scham überreicht bekam. Er trug alles freilich nicht in ein Buch ein wie unser Sammler in der Geschichte von Gómez de la Serna, sondern schrieb auf kleine Zettelchen, die er zusammen mit den Haaren in kleine Gläschen steckte. Die Geschichte ist fast zu gut, um wahr zu sein, aber sie ist wahr, insofern sie nicht

15 Derartige Beispiele finden sich in einer der Sammelleidenschaft auf den Grund gehenden Schweizer Habilitationsschrift von Sánchez, Yvette: Coleccionismo y literatura. Madrid: Ediciones Cátedra 1999.

16 Vgl. Futoransky, Luisa: Pelos. Madrid: Ediciones Temas de Hoy 1990; vgl. hierzu auch Ette, Ottmar: Mit Haut und Haar? Körperliches und Leibhaftiges bei Ramón Gómez de la Serna, Luisa Futoransky und Juan Manuel de Prada, S. 429-465. 
erfunden, sondern buchstäblich nach dem Tod des Lehrers aufgefunden wurde. Diese Anekdote verleiht auch unserem harmlosen und inoffensiven Sammler von Brüsten etwas Wahrhaftigeres, als sich viele seiner Leserinnen und Leser hätten denken können oder träumen lassen.

Es gibt jedoch noch einen weiteren Aspekt, der sich im Grunde zum Gesamtprojekt von Ramón Gómez de la Serna wie eine Mise en abîme verhält. Denn der Sammler betrachtet nicht nur die Brüste der Frau und taxiert sie, er schreibt auch den Namen der schönen Trägerin sowie ihre Adresse auf und beschreibt dann die beiden Sammelobjekte und sein Verhältnis zu ihnen. So geht also das Betrachten in ein Sammeln und das Sammeln in eine Inventarisierung und letztlich in einen Schreibprozess über, der auch das Verhältnis des Sammlers zu den von ihm gesammelten Brüsten umschreibt. Als das Ergebnis dieses Schreibens lässt sich das gesamte Buch auffassen, das uns vorliegt.

Vergessen wir dabei nicht, dass das Sammeln („colligere“) sich vom selben Etymon herleitet wie Lesen („legere“), und dass das Lesen stets immer auch ein Sammeln und das Sammeln in gleicher Weise immer ein Lesen ist. Im Deutschen macht der Begriff „Weinlese“ auf diesen etymologischen Umstand aufmerksam. Ebenso wenig sollten wir aber vergessen, dass diese Seite der Rezeption zugleich auch eine Produktion beinhaltet, insoweit Sammeln wiederum zu Schreiben und damit zur Aktivität einer kreativen Auseinandersetzung mit dem zu Beschreibenden und zu Kategorisierenden führt. Genau dies tut Gómez de la Serna in seinem in unzählige Kapitelchen gegliederten oder klassifizierenden Buch, das - wie sollten wir es dem Autor unzähliger Greguerías verdenken - aus literarischen Mikrotexten besteht.

Hierbei ist die Sammelleidenschaft das einzig Leidenschaftliche, das bei dem spanischen Avantgardisten durchbricht - ähnlich wie bei unserem Brüste-Sammler. In der Tat sind für ihn die Gegenstände, mit denen er sich sammelnd beschäftigt, so schön und auch so rein, dass er sie nicht mehr mit seinen Händen berühren zu müssen glaubt. Die Dinge sind abstrakt und er selbst ist zu einem Literaten geworden, der die Objekte nur noch vor dem inneren Auge seiner Leserschaft vorbeiführt. Das taktile Element, die olfaktische oder gustative Wahrnehmung wie auch andere Sinneswahrnehmungen sind weitgehend ausgeblendet oder doch in distanzierende literarische Ausdrucksformen verwandelt. Der Schriftsteller ist zu einem Sammler geworden, dessen Sammelleidenschaft wiederum das Schreiben erzeugt. Wir stoßen an dieser Stelle auf die Grundlagen der Schreibökonomie dieses spanischen Polygraphen.

Die Problematik des Zeigens und Verbergens, das Intervall zwischen „Fort“ und „Da“, das - wie Sigmund Freud anhand des Spielens mit seinem Enkel schon wusste - Lust erzeugt, mit anderen Worten das Demonstrative einerseits, das Exhibitionistische andererseits, das Sich-Zeigen auf der einen, das Sehen oder 
Durch-den-Blick-in-sich-Aufnehmen auf der anderen Seite, zeigt sich bereits im ersten Text, der in die Senos einging. Er eröffnet die Serie der unterschiedlichen ,Enthüllungen'. Es ist einer der eher längeren Texte, der zugleich die Problematik von Mann und Frau, von Nacktheit und Bekleidung und von jenem Zwischenraum, jenem „,interstice“ erkennen lässt, der den erotischen Blick erlaubt.

Es handelt sich um die Geschichte eines Jungen und eines Mädchens, die sich beide recht gerne sehen - wie man so schön sagt - und die auf seinen Wunsch hin vereinbaren, dass sie sich ihm nackt durch das Fenster hindurch zeigt - zumindest das nicht so obskure Objekt der Begierde, also ihre Brüste. Beide Partner sind voneinander mehrfach getrennt: durch den geschlechtlichen Unterschied, durch die einander gegenüberliegenden Häuser, durch die Distanz und die akustische Trennung aufgrund der Glasscheiben sowie vor allem auch durch ihre jeweiligen geschlechterspezifischen Rollen. Unter diesen Umständen bleibt nur noch der Fern-Sinn des Augenscheins.

Beide nehmen ihre jeweiligen, vorgegebenen Positionen ein, und das erotische Spiel fängt an. Just in diesem Augen-Blick schalten wir uns zu und verfolgen den weiteren Fortgang bis zum Ende. Selbstverständlich beginnt alles mit der Sprache der Blicke, wie sich dies bei einem voyeuristischen Drehbuch geziemt:

Schließlich schaute sie dorthin, wo ich mich befand, wobei sie an die Stelle, wo sie mich vermutete, keinen ihrer wie stets langen Blicke warf, sondern vielmehr einen kurzen und despektierlichen Blick, so als ob sie mich nicht liebte, und dann öffnete sie ihre Bluse, ließ gleichzeitig ihren Umhang herunter und zeigte mir ihre Brüste, ganz wie die Frau, die in der Tragödie sich so die Brust öffnet und sagt: „Töte mich! Stoß mir das Messer, das mir droht, hierhin!“

Sie wartete, dass ich die verbotene Photographie machte. Sie kalkulierte die Belichtungszeit, aber machte zu schnell wieder dunkel. Zu schnell? Nein. Meine arme Kleine, es wäre immer zu schnell gewesen. Um dieser Brüste ansichtig zu werden, um sie wiederzuerkennen, um sie zu erinnern, muss man viele Nächte über ihnen zugebracht haben, wie ein Bakteriologe über seinem Mikroskop.

Ich sah nichts, und ich sah dennoch eine Brust, die weder groß noch klein da hing und würdig war, die Brüste in einer Liebesbeziehung für ein ganzes Lebens zu verkörpern.

Am nächsten Morgen trat sie weinend auf den Balkon, und man sah gleich, dass sie die ganze Nacht geweint hatte. Mutig, heiter, waghalsig kam sie bis zu jenem Augenblick; aber als sie wieder in die Dunkelheit trat, fühlte sie sich beraubt, schikaniert, unnütz gemacht. Wie hatte ich nur die ganze Nacht nicht den Regen ihres Weinens an meinem Fenster hören können? ... ${ }^{17}$

Das Lust erzeugende Spiel von „Fort“ und „Da“, von Verbergen und Zeigen bleibt in dieser Mikroerzählung nicht folgenlos. Es zeigt dem Sehenden das Objekt der Begierde, das dieser im Grunde gar nicht sieht und wahrnimmt, aber doch

17 Gómez de la Serna, Ramón: Senos, S. 13. 
$\mathrm{zu}$ erkennen und sogar photographisch festzuhalten glaubt. Das Objekt wird dabei völlig fetischisiert, durch die es umgebende Kleidung isoliert und in der Tat in einen Gegenstand verwandelt, der gerade durch seine Isolierung verfügbar gemacht wird. Der erotische Körper ist der „corps morcelé“, ist nicht einfach der gänzlich unbekleidete, nackte Körper, sondern einzelne „zerstückelte“ Teile davon, die umgeben von Kleidung in ihrer inszenierten Nacktheit erscheinen. Eben dies leistet die junge Frau, indem sie aus der Entfernung, von Haus zu Haus, durch die Glasscheiben hindurch Teile ihres Körpers kurz sehen lässt, bevor diese wieder in der Kleidung wie in der Dunkelheit des Innenraumes verschwinden. Selbst die Belichtungszeit für eine im Grunde tabuisierte, den erotischen Augen-Blick auf eine unbegrenzte Dauer hin verlängernde Photographie wird einkalkuliert, um das in Raum und Zeit herausgestellte Objekt des Begehrens im Zeichen von Eros semantisch aufzuladen. Die Brüste sind „da“ - und sogleich wieder „fort“.

Wir können mit Roland Barthes den jeder Photographie innewohnenden Tod betonen, der in jedes Foto, das wir machen, eingeschrieben ist. Es ist das berüchtigte „ça a été“, jenes „Das ist gewesen“, das durch die Belichtungszeit auf der photographischen Platte wie auf unseren heutigen Smartphones jenen AugenBlick festhält, um ihm Dauer zu verleihen, ihm zugleich aber auch - wie Barthes in La Chambre claire: Note sur la photographie ${ }^{18}$ feststellte - das Momentum des Todes mitzugeben. Denn „Das ist gewesen“ sagt uns jede Photographie, indem sie uns zeigt, was einmal war und was nie wieder sein wird: was im Augenblick der Photographie bestand und längst schon nicht mehr besteht, weil die Zeit alles in ihrem Lauf mitnimmt, in ihrem Lauf zum Tode.

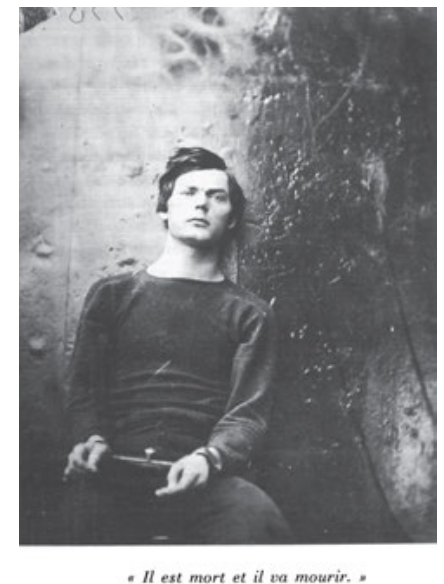

- Il est mort et il va mourir. .
Abb. 72: Die Fotografie und der Tod, Abbildung in Roland Barthes' La Chambre Claire.

18 Vgl. Barthes, Roland: La Chambre claire. Note sur la photographie. Paris: Seuil 1980. 
So erscheint mitten im Eros des Zeigens Thanatos, der Tod in der Photographie und der Tod durch die Photographie. Mit dem Zurücktreten der jungen Frau in die Dunkelheit ihres Zimmers, in die Dunkelkammer ihres Da- und Fort-Seins, fällt der Schatten des Todes über die Szenerie, deren strahlendes und begehrtes Objekt sie so wagemutig in jenem Moment war. Nun können wir ihr Weinen viel besser verstehen, muss sie doch gespürt haben, wie sehr die libidinöse Energie von Verbergen und Zeigen auf sie selbst zurückfällt und sie mit ins Dunkel reißt. Denn der gemeinsam ersehnte erotische Augenblick wird vom Tod überschattet, der in ihn eingeschrieben ist.

Das erneute Verstecken durch Kleidung und Zimmer kann diesen Tatbestand nicht mehr aufheben: Der Körper der jungen Frau hat unmittelbar seine Einheit, seine Ganzheit unwiederbringlich verloren. Der weibliche Körper ist zum Spielball der Männer oder doch zumindest eines von ihr erwählten Mannes geworden: Der aktive Akt des Zeigens wird überstrahlt und überwältigt vom aktiven Akt des Sehens. Das Zeigen kippt in ein Gesehen-Werden und damit in eine Passivität um, die ihre Leideform zu spät erkennt. So erfolgt auf metaphorischer Ebene ein Raub und zugleich ein Unnütz-Machen, das die junge Frau nicht mehr aufhalten kann: Es ist bereits geschehen, hat sich an ihr vollzogen ...

Der Mann bleibt seinerseits isoliert in seinem eigenen Raum, hinter seinen eigenen Glasscheiben; und doch hat er sich weder entblößt noch ein Stück seines Körpers freigegeben und damit aufgegeben, aus der Hand gegeben - feilgeboten jenem Blick, der letztlich ein kannibalischer Blick ist und sich das andere, die Andere einverleibt. Ein Teil des weiblichen Körper-Leibes wird über den Blick als Objekt verfügbar gemacht und dem männlichen Ich einverleibt. Damit aber ist die Zerstörung einer Leibhaftigkeit verbunden, die den Körper-Leib der Frau nun in einzelne erogene Zonen einteilt und so die Einheit in Stücke reißt. Das Weinen, die Verflüssigung des Körpers, der sich von etwas Festem in etwas Flüssiges verwandelt, belegt diesen schmerzhaften Übergang, welcher der jungen Frau freilich erst nach dem visuellen Akt, photographisch festgehalten, zu Bewusstsein kommt. Das männliche Ich nimmt noch nicht einmal die Liquidierung, die Verflüssigung des weiblichen Körper-Leibes im Regen der Nacht an den eigenen Fensterscheiben wahr.

An dieser Stelle möchte ich meine Deutung einer ausgewählten Passagen aus Ramón Gómez de la Sernas durchaus einflussreichem Buch abbrechen oder beenden. Unverkennbar ist zum einen, dass sein Schreiben sich des erotischen (und nicht pornographischen) Themas annimmt, um damit ein literarisches Darstellungstabu zu brechen, ein mimetisches Verbot zu übertreten, das längst hinfällig geworden ist. Ein Blick in die Literaturgeschichten freilich zeigt uns, dass die erotische Literatur - vom Gilgamesch-Epos angefangen - so alt ist wie die Literatur selbst. Don Ramón war hier nicht mehr als ein Fortführer jener 
Immoralismus-Prozesse, welche die Literaturen des 19. Jahrhunderts mitgeprägt haben.

Es sollte nicht lange dauern, bis gerade auch unter dem Druck der französischen Surrealisten, für die ein Marquis de Sade in der Tat der „göttliche Marquis“ war, andere Teile des weiblichen Körpers auf literarische Weise kannibalisch einverleibt und zum Gegenstand und Motor avantgardistischen Schreibens wurden. Für den männlichen Körper erfolgte dies zeitversetzt später. Der Körper des oder der begehrten Anderen wird nicht erst mit den Avantgarden zum Antrieb eines wie auch immer gearteten heterosexuellen oder homosexuellen Schreibens. Wir könnten dies parallel zu Don Ramóns Senos anhand von Louis Aragon und seinem durch den Titel brüskierenden Buch Le con d'Irène überprüfen, dem ich mich hier leider nicht zuwenden kann.

Doch bleiben wir noch für einen Augenblick bei den Avantgardisten jener Stunde! Die Verfügbarmachung des weiblichen Körpers durch den männlichen Blick ist auf der einen Seite tabuzerstörend. Auf der anderen Seite aber errichtet dieser Blick wiederum neue Tabus gegenüber dem männlichen Körper und dessen literarischer Darstellung wie auch zum anderen gegenüber dem weiblichen Blick auf die Nacktheit eines weiblichen, eines männlichen oder eines andersgeschlechtlichen Körpers einschließlich der Hermaphroditen, die eine lange Literaturgeschichte besitzen. Diese Problematik wird auf der weiblichen Seite, wenn ich recht sehe, in radikaler Weise erst durch Anaïs Nin in ihren Tagebüchern und nicht zuletzt in ihrem Band Delta of Venus subvertiert und in Frage gestellt. War dies ein Weg hin zu einer pornographischen Literatur?

Nein, eher $\mathrm{zu}$ einer Form erotischer Literatur, die einen kannibalischen Grundzug besitzt. Denn das Spielen mit dem Körper des Anderen ${ }^{19}$ erzeugt zwar auch den Körper des Anderen, bringt ihn aber letztlich wieder zum Verschwinden und sogar zu einer Auflösung im Ich, das sich dieses Prozesses selbst gar nicht bewusst sein muss. Avantgardistisches Schreiben wird an dieser Stelle bei Ramón Gómez de la Serna zu einer Inbesitznahme des Territoriums Frau, um von einer auf diese Weise besessenen Frau die Welt ebenso wieder neu nach ihrer willentlichen Zerstörung zusammenzusetzen wie auch den Körper der Frau selbst. Die Grenzen der historischen Avantgarden sind an dieser Stelle offenkundig. Die Frau wird zum Puzzle, dessen Zusammensetzung zur einstmals verlorenen Einheit allein dem Manne möglich zu sein scheint. Dies ist aus der heutigen Sicht nach der Postmoderne mehr als nur politisch unkorrekt. Die historische Avantgarde ist die Vorhut des männlichen Blickes, dessen Dominanz erst später durch neue

19 Vgl. hierzu Krechel, Ursula: Spielen mit dem Körper des Vaters. Essay. Frankfurt am Main: Suhrkamp 1992. 
Avantgarden wenn nicht gebrochen, so doch nachhaltig hinterfragt und aufgebrochen wird. Auf diesem Weg wie auf vielen anderen Wegen ist eine eingehendere Beschäftigung mit dem Surrealismus unverzichtbar. Doch lassen Sie uns zuvor noch kurz mit einem anderen europäischen Autor beschäftigen, der gemeinhin nicht unter avantgardistischen Gesichtspunkten betrachtet wird! 